\title{
Exploring Consumer Perceptions toward the Use of Me-Ality Body Scanner for Clothing Selection in U.S. Shopping Malls
}

\author{
Young-A LEE* \\ lowa State University, Ames (IA), USA \\ http://dx.doi.org/10.15221/13.372
}

\begin{abstract}
The purpose of this exploratory study was to gain knowledge about consumer perceptions toward the use of $3 \mathrm{D}$ body scanning technology for their clothing selection. The specific objectives were: 1) to explore U.S. consumer's clothing fit and sizing issues, 2) to understand the level of consumer satisfaction about his/her current clothing fit; 3) to explore the consumer perceptions for the use of the Me-Ality body scanner; and 4) to examine the consumer's level of motivation to use this technology in the future. A convenience sample of 18 consumers was recruited from two of the purposefully chosen U.S. Midwestern shopping malls that equipped Me-Ality scanners providing sizing recommendations to consumers based on their body scan. After the completion of their Me-Ality body scan experience, potential study participants were asked to complete survey questionnaires to understand their usage of this technology to find better-fitted clothing during their shopping experiences. Participant's ages ranged from 18 to 28 . The sample consisted of $39 \%$ of males and $61 \%$ of females, and $72.2 \%$ of White European Americans and $27.8 \%$ of African American. The majority resided in the Midwest (94.4\%) and had attended at least some college (77.8\%). Both quantitative and qualitative data analyses were used for this study. The results of this study indicate that most participants were satisfied with their current clothing fit while recognizing apparel sizing was different among brands. Waist, pant length, and the bust for females were common areas of fit dissatisfaction, with participants often commenting that proper fitting jeans and pants were the clothing that were most difficult to find. Although participants were mostly neutral about the perceived usefulness of body scanning, almost all believed the scanning process and body scanner were easy to use. The frequent reasons for participants to use the scanner were to check their right clothing size, for fun, and because another person asked them to try the body scanning. Participants had an overall positive opinion of 3D body scanning and expressed their interest to use this technology in the future, especially obtaining their accurate sizing information in a retail store setting. During the data collection, researchers observed that the employees operating the Me-Ality scanners had to try to convince people walking by to stop and do a scan. One worker commented the most challenging part was getting people to stop and do it saying, "Most people don't know what the body scanner is, so they don't want to try it." Many of the Me-Ality customers were children and teenagers who were at the malls for leisure purposes and had the time to devote to the scanning process. Since young people have been found to be more technologically oriented, further research should be done in this age group. Further research is also recommended on other Me-Ality consumers in other geographic locations to provide a more representative population. With more consumer awareness and accessible locations, 3D body scanning technology could become more prevalent in the everyday consumer shopping experience.
\end{abstract}

Keywords: $3 d$ body scanning, clothing, consumer perception, Me-Ality

\section{Introduction}

\subsection{Background}

There are numerous uses of emerging technology in the apparel industry such as customer service kiosks, retail store assistants attached to shopping carts, mobile phones catering to individual consumer needs, and social media (e.g., Facebook, Twitter, YouTube) as a new outlet for advertising, marketing, and information sharing. Lastly, 3D body scanning technology has provided the exact body measurement data that can be used by consumers to make custom fitting garments or find the brand that best fits their body. Body scanning can also be used in virtual try-on applications, co-design websites, computer-aided design (CAD), and in personal shopping among other applications [1]. While most body scanners are located in research laboratories or public areas like shopping malls and/or retail stores, research has also being done using home body scanners [2]. Loker, Ashdown, and Carnrite predicted the entire clothing design process to be transformed with the Internet, including 3D personal body scans and compatible CAD software, virtual try-on and fit technologies, and emerging virtual tactile capabilities [3].

\footnotetext{
* ylee@iastate.edu; +1- 515-294-7826; 1073 LeBaron Hall, lowa State University
} 
Retail companies also have the opportunity in the future to perform size-specific analyses of body scan data of the firm's target market to adjust ready-to-wear sizing to improve apparel fit [4].

The use of 3D body scanning in shopping malls and retail stores is providing customers with sizing information to improve and expedite their shopping experience. The Canadian-based company, Unique Solutions, has placed size-matching stations in common areas in U.S. shopping malls [5]. At the time of the study, the scanners were placed in 24 locations primarily on the East and West coasts with the heaviest concentrations in the cities of Los Angeles and New York [6]. The number of scanner locations has decreased in recent years of 2013 [6]. At one time there were over 50 scanners in U.S. shopping malls [5]; however, in 2013 there are only a few scanner locations within Bloomingdale's department stores specializing in women's denim recommendations. (e.g., J Brand, 7 For All Mankind, True Religion, Hudson, Citizens of Humanity) [7].

The Me-Ality and Bloomindale's partnership is not the first instance of department stores looking to offer size recommendation technology. In 2011, Macy's introduced True Fit technology to its e-commerce site. This technology asked users to complete a three-step profile in which they selected brands and sizes that fit them best, indicated their body shape, and recorded their height and weight. The information was then combined with customer shopping behavior on the site to determine what products were likely to fit [8]. Clothes Horse is another company that has developed an embeddable widget for online retail outlets. When a customer shops on the ecommerce site of one of Clothes Horses' partners, like the menswear shop Bonobos, he or she is prompted to answer questions similar to the True Fit questionnaire indicating height, weight, and sizes he or she wears in other clothing brands [9].

Unique Solution's market research shows participating retailers increase sales when participating in their retail sizing solution service [10]. The size information from the scanner can also be used by online shoppers who can create a profile on the Me-Ality website that provides even more clothing options based on their scan. This may prove highly beneficial to the $80 \%$ of consumers that won't buy online due to uncertainty of fit according to a study of 4,000 Me-Ality users [11]. Although the majority of users are women, men are also experimenting with the new technology [12]. A company with a similar size-matching concept, London-based Bodymetrics, has also placed their scanning pods in U.K. and U.S. retailers. Additionally, Bodymetrics is developing technology that could be used to scan consumers with sensors on their televisions at home [13].

The industry needs to understand how quickly consumers will adopt these new technologies and their desire to incorporate them into their shopping habits. Specifically for this study, understanding consumers' perception to use 3D body scanning technology as his/her shopping guide will lead the apparel industry to prepare the further usage of this technology in various retail settings, as well as enhance the consumers' overall fit satisfaction.

\subsection{Purpose of the Study}

The purpose of this study was to gain knowledge about consumer perceptions of the use of Me-Ality body scanner in the apparel industry. This study was unique in the fact it surveyed the perceptions of actual customers in real-life settings (e.g., shopping malls) compared to the majority of previous studies that have been done in hypothetical or laboratory settings. The four research objectives of the study were: 1) to explore U.S. consumers' clothing fit and sizing issues; 2 ) to understand the level of consumer satisfaction about his/her current clothing fit; 3) to explore the consumers' perception for the use of the Me-Ality body scanner at various U.S. shopping malls; and 4) to examine the consumers' motivation level to use this technology in the future. For this study the Technology Acceptance Model (TAM) model was adopted [14] and modified to include the variables of level of fit satisfaction and level of fit issues or concerns in addition to the variables of perceived usefulness, perceived ease of use, attitude, and intended use.

\section{Research Methods}

Survey methodology was used for this study on understanding consumer perceptions toward the use of 3D body scanning. Consumers who visit a shopping mall which has the Me-Ality 3D body scanner were asked to fill out a survey questionnaire after the completion of their scan. Observational approach was also taken to understand consumer's shopping behavior. 


\subsection{Study Sample}

A convenience sample of 18 consumers at two shopping malls near the St. Louis area in Missouri, USA was recruited for this study. The shopping malls were purposefully chosen by the following criteria: proximity of geographical location from researchers (no longer than a 6-7 hour drive) and acquisition of the Me-Ality body scanner in the mall at the time of this study. Twelve participants were surveyed over a 6 hour time period at the first mall, while 6 participants were surveyed over a 4 hour time period at the second mall. The two St. Louis locations used in the study are currently no longer listed on the Me-Ality website [6].

The sample consisted of 7 males (38.9\%) and 11 females (61.1\%). The average age was 28.83 years with $77.8 \%$ of the sample between the ages of 18 and 28 . Thirteen participants were white or European American (72.2\%) with the other 5 participants being African American (27.8\%). The majority of the participants $(94.4 \%)$ resided in the Midwest. The majority of participants $(77.8 \%)$ had attended at least some college, if not obtained a degree. The majority of participants had body mass indices (BMI) in the "overweight" category between 25 and 29.9; the "normal weight" category with BMls between 18.5 and 24.9 (35.3\% of the sample), and the remaining $11.8 \%$ of the sample fell in the "obese" category with BMls greater than 30 .

\subsection{Survey Instrument}

A survey questionnaire was developed and distributed in the malls, targeting the consumers that came out of the Me-Ality scanner. The survey items included clothing fit and sizing issues, consumer satisfaction about clothing fit, perception for the use of the Me-Ality scanner during their shopping, motivation to use this technology in the future, and demographic information (e.g., age, gender, geographical location, education, ethnicity, weight, height). The quantitative survey items were rated on a 7-point Likert-type scale, ranging from "1" as Strongly Disagree, "4" as Neutral, to "7" as Strongly Agree. Qualitative survey items were included in the form of open-ended questions.

Items measuring clothing fit and sizing issues were adopted from Weidner [15]. Items measuring clothing fit satisfaction with certain areas of the body were adopted from LaBat and DeLong's study [16]. The items asked the level of fit satisfaction participants had for the various body areas. Items measuring perceived usefulness, perceived ease of use, attitude, and intention were adopted and modified from Davis's study [14], Moon and Kim's study [17], and Ngai, Poon, and Chan's study [18].

\subsection{Data Collection and Analysis Procedure}

\subsubsection{Data collection procedure}

For this study, the Me-Ality body scanners were used because of its uniqueness in how they provide sizing recommendations to consumers based on their 3D body scan in both the retail store and online settings. After filling out a form with general demographic information and removing bulky clothing, the consumer stands in the kiosk for about 20 seconds while a vertical "scanning wand" rotates around the body, emitting safe, low-power radio waves from 196 antennas, gathering data from 200,000 different points on the body [19]. Within minutes, the kiosk prints off suggestions for various cuts, styles, price points, and brands of a product. Me-Ality obtains stores' sizing and style information by partnering with them. Companies pay a fee to participate, but the scanning is free to the customer [12]. Me-Ality's sizing software uses a variety of measurements and body information from the customer's scan to then compare against fit specifications of each style and brand in their program. The software can then rank the customer's best fitting clothes [6].

Before the data collection, the Me-Ality managers of the two St. Louis area malls were contacted to ask the current consumer usage of their scanner and obtain any necessary information. Researchers also communicated with the managers to arrange time to visit the mall for this study. The data collection was done in March 2013. After completing the Me-Ality body scan, customers were asked to complete the survey. At the beginning of the survey, each participant was asked to review the consent form and provided full information of the study. Upon completion of the survey, the document was collected and participants were thanked for their time.

\subsubsection{Data analysis procedure}

Quantitative analysis using the SPSS software was used to obtain descriptive statistics, frequencies, correlations, simple T-tests, and linear regressions among variables. Data from open-ended questions was analyzed using content analysis, one of qualitative analysis approaches, to pull out important 
themes among consumer responses. The frequencies of these themes were then found to determine important factors for the consumer.

\section{Results and Discussion}

The results of this study are organized by research objective.

\subsection{Me-Ality Scan Output}

The output of a completed Me-Ality scan is seen below. The shopping guide was printed after the scan and contains clothing options from stores located in the specific mall location. After completion of a scan at the mall location, users have access to an online Me-Ality account that provides additional brands and style options.

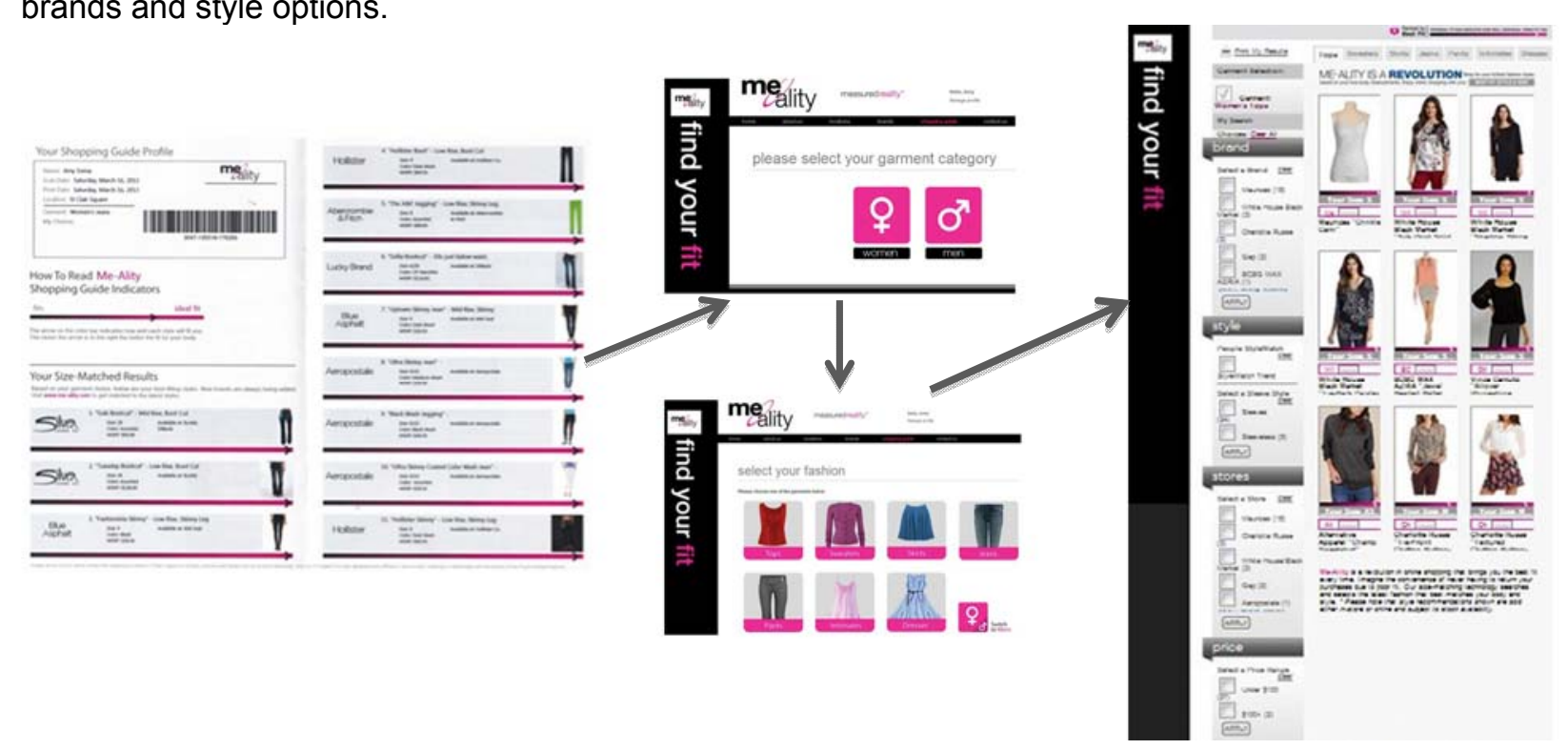

Fig. 1. Consumer's Me-Ality scan outputs

\subsection{Exploring U.S. Consumers' Clothing Fit and Sizing Issues}

When asked what the participants' major fit concerns were when they purchase clothing, the fit of the waist was most frequently mentioned. Length, the breast area, and the fit of jeans and pants in general were also frequently mentioned as areas of fit concern.

Quantitative findings suggest that most people (77.8\%) believed that garment sizes are not the same across all brands of ready-to-wear apparel and that most people (61.2\%) agreed that they wear a different size in one brand's garment as compared to another brand's similar garment. Despite this recognition of sizing differences among apparel brands, the majority of participants $(50.1 \%)$ said they were satisfied with the way most of their clothing fit, and the majority $(50 \%)$ also said they generally didn't have problems finding clothing that fit well.

In general, participants in the "overweight" and "obese" categories based on BMI had lower clothing fit satisfaction $(M=4.64)$ than participants in the "normal weight" category $(M=5.17)$. Female participants also had lower clothing fit satisfaction $(\mathrm{M}=4.64)$ and believed clothing fit differed between brands $(M=5.45)$ more than male participants $(M=5.43$ and $M=3.86$, respectively). There was a significant linear relationship (.928) between BMI category and the item "I wear a different size in one brand's garment as compared to another brand's similar garment." Another significant linear relationship (.732) was found between BMI category and the item "I have problems finding clothing that fits well." A significant correlation of .625 was found between the items "I wear a different size in one brand's garment as compared to another brand's similar garment" and "I have problems finding clothing that fits well." This correlation may suggest differences in brand sizes create difficulties for consumers when shopping for clothing. Lastly, a significant linear relationship (.704) between ethnicity and the item "I am satisfied with the way most of my clothing fits" was found. These linear relationships suggest specific demographic variables involved in clothing fit and sizing issues. 


\subsection{Understanding the Level of Consumer Satisfaction about His or Her Clothing Fit}

As found previously [15], participants were generally satisfied with their current clothing fit. The majority was satisfied with the fit in the following body areas: bust, shoulder, neckline, sleeve length, upper arm, calf, buttocks, and waist length. Most participants were neutral about the fit of the hip, and were dissatisfied with the fit in the waist and pant length. No significant linear relationship or significant correlations were found between fit issues/concerns and attitude towards the use of 3D body scanner. Participants in the "normal weight" BMI category were significantly more satisfied with the fit in the bust $(M=5.00)$ than participants in the "overweight" and "obese" categories $(M=3.91)$. Males were generally more satisfied with clothing fit in each specific body area compared to females. Males were especially more satisfied in the bust area $(M=5.00)$ than females $(M=3.82)$, the waist area (males $M=4.67$; females $M=2.90$ ), and in pant length (males $M=5.14$; females $M=2.82$ ).

\subsection{Exploring the Consumers' Perception for the Use of the Me-Ality Body Scanner at Various U.S. Shopping Malls}

Predominantly, participants were neutral about the perceived usefulness of the body scanner. Most other responses from participants that were not neutral were positive. For example, $88.3 \%$ of participants were either neutral or agreed that overall, the body scanner was useful to their shopping experiences. There were no dramatic differences between BMI categories or gender in terms of perceived usefulness. There was also no significant linear relationship between perceived usefulness and attitude, but there were significant positive correlations between the two variables.

Perceived ease of use for the body scanner was overwhelmingly positive, with $94.2 \%$ of participants agreeing that the body scanning process is clear and understandable. Overall, $82.4 \%$ of participants believed that the body scanner was easy to use. There were no dramatic differences between BMI categories or gender in terms of perceived ease of use. No significant linear relationship between perceived ease of use and attitude towards the body scanner was found, but significant positive correlations between the two variables were identified. There was a positive correlation of .553 between the items "Overall, I believe the body scanner is easy to use" and "Overall, I like using the body scanner." When asked the participants' main reasons for using the body scanner the most frequent response was to find or check their right clothing size. Others frequently mentioned were that they did the scan for fun or they were asked to do by another person.

\subsection{Examining the Consumers' Motivation Level to Use 3D Body Scanning Technology in the Future}

The participants had a positive opinion of 3D body scanning. Overall, $94 \%$ of participants liked using the body scanner. Most participants (69.9\%) thought using the body scanner was fun, and $76.4 \%$ of participants believed using the scanner was a good and pleasant idea. The majority of participants $(47 \%)$ intended to increase their use of the body scanner in the future. The same percentage of participants said they would frequently use their sizing information from the body scanner in the future when shopping in stores and $58.8 \%$ would recommend others to use the scanner. Generally, participants with higher BMls had a slightly more positive attitude about body scanning and had greater intentions to use body scanning in the future. Females also had a slightly more positive attitude and greater intention for use in the future than males. No significant linear relationship between attitude and intended future use was found, but significant, positive correlations were found between these two variables.

\section{Conclusions}

The results of this study indicate that while participants recognized apparel sizing is different among brands, most were satisfied with their current clothing fit and generally didn't have problems finding clothing that fit well. The most common areas of fit dissatisfaction were the waist, pant length, and the bust for females, with participants often commenting that proper fitting jeans and pants were the garments that were most difficult to find.

Although participants were mostly neutral about the perceived usefulness of Me-Ality body scanning, almost all believed the scanning process and body scanner were easy to use. The most frequent reasons for participants to use the scanner were to check their right clothing size, for fun, and because another person asked them to try the body scanning process. In accordance with previous literature $[20,21,22,23,24]$, participants had an overall positive opinion of 3D body scanning and liked using 
the body scanner. The majority of participants intended to use the body scanning technology again in the future, especially for their sizing information in the retail store setting.

The results of this study are very limited by the use of a small convenience sample of Me-Ality consumers in two shopping malls in the St. Louis area. The small number of participants can be attributed to the fact that people did not seek out the body scanning service, and so there were a small number of consumers to begin with. The employees operating the Me-Ality scanners had to try to convince people walking by to stop and do a scan. Getting people to take the time is difficult in today's busy, time-conscious society. One worker at the scanning booth said the most challenging part was getting people to stop and do it saying, "Most people don't know what the body scanner is, so they don't want to try it." This created difficulty when recruiting participants, because it was challenging to get reluctant customers to spend an additional 10 minutes filling out the survey questionnaire. Another possible explanation for the small sample size was that the survey was not distributed to consumers under the age of 18. Many of the Me-Ality customers were children and teenagers who were at the mall for leisure purposes and had the time to devote to the scanning process. Since young people have been found to be more technologically oriented, further research should be done in this age group. Further research is also recommended on other Me-Ality consumers in other geographic locations to provide a more representative population.

The observations and results of this study have provided a few suggestions for the future implementation of 3D body scanning technology. As time progresses and the technology improves, 3D body scanning will likely become more prevalent in the retail setting. As younger, technology savvy consumers age, there will be more demand and acceptance of this technology in an integrated shopping experience. A major obstacle faced by apparel companies is making the consumer aware of 3D body scanning technology. At the time of this study, most people did not know anything about the technology, so increased awareness may lead to an increase in use.

Although the number of current locations has decreased, Me-Ality has recently attempted to raise more brand awareness by partnering with Bloomindale's department stores in the placement of 3D body scanners in selected stores [6]. This targeted strategy to locate the Me-Ality scanners in Bloomingdale's may also prove to create more comfort for consumers since previous studies have indicated consumers would prefer to be scanned in retail stores than mall kiosks [20]. With more consumer awareness and accessible locations, 3D body scanning could become more prevalent in the everyday consumer shopping experience.

\section{References}

1. Lee, Y. A., Damhorst, M.L., Lee, M., Kozar, J., Martin, P., (2011): "Older women's clothing fit and style concerns and their attitudes toward the use of 3D body scanning", Clothing and Textiles Research Journal, Vol.30, No.2, pp.102-118.

2. Weiss, A., Hirshberg, D., Black, M., (2011): "Home 3D body scans from noisy image and range data", 2011 IEEE International Conference on Computer Vision (ICCV), pp.1951-1958.

3. Loker, S., Ashdown, S., Carnrite, E., (2008): "Dress in the third dimension: online interactivity and its new horizons", Clothing and Textiles Research Journal, Vol.26, No.2, pp.164-176.

4. Loker, S., Ashdown, S., Schoenfelder, K., (2005): "Size-specific analysis of body scan data to improve apparel fit", Journal of Textile and Apparel Technology and Management, Vol.4, No.3, pp.1-15.

5. Brown, R., (2012a): "Me-Ality: sizing up the customer", Women's Wear Daily, accessed from: http://www.wwd.com/markets-news/denim/me-ality-sizing-up-the-customer-5885292.

6. Me-Ality Corporate Website (accessed 2013): www.me-ality.com

7. Indvik, L., (2013): "Bloomingdale's installs body scanners to help you find jeans that fit", Mashable, accessed from: http://mashable.com/2013/04/09/bloomingdales-me-ality/

8. Kessler, S., (2011): "Macy's adds startup 'True Fit' sizing technology to its site", Mashable, accessed from: http://mashable.com/2011/10/04/macys-truefit/

9. Indvik, L., (2012): "Clothes Horse wants to help you find clothes that fit", Mashable, accessed from: http://mashable.com/2012/07/20/clothes-horse/

10. Polvinen, E. (2012). "Intellifit bodyscan technology for public sizing and fit services", Virtual Fashion Technology, accessed from:

http://fashiontech.wordpress.com/2012/07/07/intellifit-bodyscan-technology-for-public-sizing-and-fi t-services/ 
11. Strugatz, R. (2012). "Me-Ality takes personalization to the masses", Women's Wear Daily, accessed from:

http://www.wwd.com/retail-news/direct-internet-catalogue/mealitys-fit-solution-6333603

12. Bauknecht, S., (2012): "Me-Ality body scanner helps shoppers find the perfect fit", Pittsburgh Post-Gazette, accessed from:

http://www.post-gazette.com/stories/life/fashion/me-ality-body-scanner-provides-shoppers-with-list s-of-stores-and-the-sizes-ideal-for-their-figures-640990/

13. Brown, R., (2012b): "Bodymetrics deploys digital matchmaker for jeans buying", Women's Wear Daily, accessed from:

http://www.wwd.com/markets-news/denim/bodymetrics-deploys-digital-matchmaker-5811179.

14. Davis, F., (1989): "Perceived usefulness, perceived ease of use, and user acceptance of information technology", MIS Quarterly, Vol.13, No.3, pp.319-340.

15. Weidner, N., (2010): "Vanity sizing, body image, and purchase behavior: a closer look at the effects of inaccurate garment labeling", Masters Theses and Doctoral Dissertations, Paper 275 (http://commons.emich.edu/theses/275).

16. LaBat, K., DeLong, M., (1990): "Body cathexis and satisfaction with fit of apparel", Clothing Textile Research Journal, Vol.8, No.2, pp.43-48.

17. Moon, J. W., Kim, Y. G., (2001): "Extending the TAM for a World-Wide-Web context. Information and Management", Vol.38, pp.217-230.

18. Ngai, E. W. T., Poon, J. K. L., Chan, Y. H. C., (2007): "Empirical examination of the adoption of WebCT using TAM", Computers and Education, Vol.48, pp.250-267.

19. Huffington Post "Me-Ality, virtual fitting room, gives full body scans to mall shoppers" (accessed 2012):

http://www.huffingtonpost.com/2012/04/30/meality-kiosk-booth-mybestfit-body-scan_n_1464782.h tml

20. Loker, S., Ashdown, S., Cowie, L., Schoenfelder, K., (2004): "Consumer interest in commercial applications of body scan data", Journal of Textile and Apparel Technology and Management, Vol.4, No.1, pp.1-13.

21. Loker, S., Cowie, L., Ashdown, S., Lewis, V. D., (2004): "Female consumers' reactions to body scanning", Clothing and Textiles Research Journal, Vol.22, No.4, pp.151-160.

22. Faust, M., Carrier, S., (2009): "3D body scanning's contribution to the use of apparel as an identity construction tool", Digital Human Modeling: Lecture Notes in Computer Science, No.5620, pp.19-28.

23. Park, J., Nam, Y., Choi, K., Lee, Y., Lee, K., (2009): “Apparel consumers' body type and their shopping characteristics", Journal of Fashion Marketing and Management, Vol.13, No.3, pp. 372-393.

24. al-Mousa, M. (2011): "Saudi Arabian consumer's interest in commercial application of 3D body scanner in the apparel market", International Journal of Consumer Studies, Vol.35, No.6, pp.688-694. 